\title{
Impact of green initial cuttings of vegetative- active grafting points of cherry on rooting and its period, rods, and growth controlling plant substance concentration
}

\author{
Zaynilabiddin Abdikayumov $^{1 *}$ and Diloram Yulchieva ${ }^{1}$ \\ ${ }^{1}$ Tashkent State Agrarian University, 100140, Tashkent province, Uzbekistan
}

\begin{abstract}
This scientific paper presents the results of experiments on the propagation of vegetatively propagated clone grafts of cherries from green cuttings. In the experiment, the effect of the concentration of indolymic acid (IMK), the time of preparation of green cuttings and the part of the stem from which the green cuttings were obtained, on the growth of vegetatively propagated stems of cherries from green cuttings was studied. The object of study was the weakly growing vegetatively propagated VSL2 (Krimsky-5) and CAB-6P grafts of cherries. The cuttings were treated with water concentrations of $20,40,60,80,100 \mathrm{mg} / \mathrm{l}$ to determine the optimal concentration of the growth regulating agent - IMK. Rapid acceleration of rhizogenesis processes and high root yield (78-81\%) in green cuttings of cherry clone grafts were noted in the variant treated with IMK $80 \mathrm{mg} / 1$ water concentration. The rapid and early regeneration processes in green cuttings using the optimal concentration of IMK ensured that their conditional body diameter reached a standard $(6-7 \mathrm{~mm})$ size by the time of cutting grafts. In this experimental variant, the amount of plants that can be grafted has reached about $89 \%$ of the total number of plants that have taken root.
\end{abstract}

\section{Introduction}

Cherries are the earliest ripening legumes in Uzbekistan, so the demand for them is very high. Demand for cherries is much higher not only in our country, but also in foreign countries $[1,2]$. Therefore, the expansion of these fruit plantations, the production of quality, competitive and high yields from them can be an important factor in significantly increasing the export potential of our country. However, today the total area of cherry orchards does not exceed $14 \%$ of the existing orchards in the country. In addition, most of them are traditionally strong growing (extensive) gardens, and to this day there is a strong need for renewal [3].

The very small area of intensive cherry orchards in our country can be explained by the fact that until recently, local strong-growing low-growing cherries, ordinary sour cherries

* Corresponding author: z.abdikayumov@,yandex.ru 
and cherry seedlings of 'Drogana jeltaya' variety were used as grafts. Intensive cherry orchards under construction in recent years are grown on clone grafts such as VSL-2 (Krimsky-5), CAB-6R, Maxima Delbard-14, Gisela-5, Gisela-6, most of which are introduced from foreign countries. In our country, there are opportunities for rapid propagation of these clone grafts in various ways, the implementation of which opens up broad prospects for the production of weakly growing cherry seedlings at low cost, as well as saving large amounts of currency on imported seedlings [1-4].

Propagation of clone grafts of fruit plants from green cuttings has been successfully used in horticulture in recent years. In this case, especially the sensitivity of these plants to the treatment with growth agents provides a higher efficiency of propagation by green cuttings [5-7].

The sensitivity of a number of fruit plants that are not prone to vegetative propagation to treatment with growth-regulating substances has been proven in the experiments of many scientists in recent years [8]. Under the influence of these substances is observed hydrolysis of starch, as well as acceleration of the arrival of sugars and nitrogenous substances from the leaves to the lower parts of the cuttings [9]. This results in an abundant accumulation of nutrients in the lower part of the stem and activation of meristem cells. This results in the regeneration of additional roots in green cuttings transplanted into the substrate $[6,10]$.

In recent years, growth inhibitors such as indoleyl acid (IMK), indoleyl acetic acid (ISK), alpha and beta-naphthyl acetic acid (NUK) have been widely used as such substances $[11,12]$.

In addition, there are reports that mival, cherkas, germatranol and other substances have also been tested in fruit plants and good results have been obtained. The peculiarities of vegetatively propagating clone grafts of cherries from green cuttings have been very well illuminated in several studies [7-11].

The aim of the study was to determine the effect of growth-regulating substance concentration, pruning time, and stem portion on the vegetative propagation of vegetatively propagated clone grafts of cherries from green cuttings.

\section{Materials and methods}

The object of study is the green cuttings of VSL-2 (Krimsky-5) and CAB-6P grafts of vegetatively propagated cherries, the growth inhibitor - different concentrations of IMK $(20,40,60,80,100 \mathrm{mg} / \mathrm{l}$ of water), cutting time and rod part served.

The study was conducted on the basis of methods recommended by Buriev, Enileev and others [3], Ermakov [5], Tarasenko [10] and other scientists.

Studies of many scientists have shown that the treatment of vegetatively propagated grafts with growth-regulating substances in their basal part of green cuttings gives good results $[1,2,10]$.

Therefore, in this experimental variant, green cuttings of cherry grafts were prepared 8$12 \mathrm{~cm}$ long and treated with solutions of IMK at a concentration of 20, 40,60, 80, $100 \mathrm{mg} / 1$ water for 12 hours before planting in their basal part. After treatment in a growth control solution, the cuttings were rinsed with clean water before planting. Processed cuttings were planted at a depth of 3-4 cm in substrates cassettes filled with a mixture of river sand and humus in a 1:1 ratio, specially prepared for the top $5 \mathrm{~cm}$ of pure coarse-grained sand and the bottom.

The unique advantage of planting in cassettes is that when the conditional body of rooted cuttings reaches $6-7 \mathrm{~mm}$, it is possible to graft them in the same year. This eliminates the need to transplant them into the first field of the nursery in late autumn or early spring. The total area of seedling cultivation is reduced from 3 to 2 years. In addition, grafting seedlings planted in cassettes increases the productivity and convenience of grafts. 
This allows performing grafts work in one place, on a special desktop. It is also more convenient to transplant cassette plants to the first field of the nursery in early spring, and the plant permeability is also much higher than in the traditional method.

Growing of grafts was carried out in a film structure with controlled internal microclimate - artificial fog.

In experiments to study the time of pruning and the effect of part of the stem on rooting, green cuttings of vegetatively propagated cherries VSL-2 (Krimsky-5) and CAB-6P were separated from the lower, middle and tertiary apical parts of the branch every ten days from the first ten days of May to the end of June. -prepared separately and studied their rooting in an artificial substrate in an indoor microclimate-controlled structure.

\section{Results and discussion}

It is known that in recent years, many positive results have been achieved in the propagation of fruit, ornamental and other plants from the vegetative way - green cuttings. As noted above, the main reason for this was the sensitivity of many fruit plants, which are not prone to vegetative propagation, to treatment with growth-regulating substances.

However, it should be borne in mind that green cuttings of plants, which tend to reproduce in different vegetative ways, show different sensitivity to processing with different concentrations of growth-regulating substances. The results of the experiment showed that treatment with aqueous solution of indoleyl acid in different concentrations before planting on the green cuttings of cherry plant seedlings accelerated the regeneration process (Table 1).

Table 1. Influence of treatment of green cuttings of vegetatively propagated cherry grafts with different concentrations of IMK on rhizogenesis (2017-2020).

\begin{tabular}{|c|c|c|c|c|}
\hline \multirow[b]{2}{*}{ Experiment options } & \multicolumn{3}{|c|}{ From planting cuttings: } & \multirow{2}{*}{$\begin{array}{c}\text { Amount of } \\
\text { cuttings } \\
\text { taking root, } \\
\%\end{array}$} \\
\hline & $\begin{array}{c}\text { until callus } \\
\text { formation } \\
\text { begins, days }\end{array}$ & $\begin{array}{l}\text { until gross root } \\
\text { formed, days }\end{array}$ & $\begin{array}{l}\text { until branches } \\
\text { begin growing, } \\
\text { days }\end{array}$ & \\
\hline \multicolumn{5}{|c|}{ CAB - 6P } \\
\hline $\begin{array}{l}\text { Cuttings treated with } \\
\text { water - cont. }\end{array}$ & 28 & 41 & 48 & 42 \\
\hline IMK $-20 \mathrm{mg} / \mathrm{l}$ & 22 & 29 & 31 & 65 \\
\hline IMK $-40 \mathrm{mg} / \mathrm{l}$ & 17 & 23 & 27 & 71 \\
\hline IMK -60 mg/l & 15 & 20 & 25 & 73 \\
\hline IMK -80 mg/l & 11 & 18 & 21 & 78 \\
\hline IMK $-100 \mathrm{mg} / \mathrm{l}$ & 12 & 19 & 21 & 71 \\
\hline \multicolumn{5}{|c|}{ VSL-2 (Krimsky-5) } \\
\hline $\begin{array}{l}\text { Cuttings treated with } \\
\text { water - cont. }\end{array}$ & 25 & 38 & 42 & 46 \\
\hline IMK $-20 \mathrm{mg} / 1$ & 18 & 25 & 25 & 68 \\
\hline IMK $-40 \mathrm{mg} / \mathrm{l}$ & 12 & 18 & 23 & 74 \\
\hline IMK -60 mg/l & 11 & 17 & 22 & 77 \\
\hline IMK -80 mg/l & 8 & 16 & 19 & 81 \\
\hline IMK $-100 \mathrm{mg} / \mathrm{l}$ & 11 & 16 & 20 & 73 \\
\hline
\end{tabular}

Experiments have shown that the rhizogenesis of green cuttings of grafts and the restoration (regeneration) of their surface part is somewhat more rapid than control in the variants treated with a growth control agent. For example, callus formation in the phloem portion of treated cuttings occurred 6-17 days earlier in the average CAB-6P graft than in control, branch formation averaged 17-27 days earlier, and gross root formation averaged 
12-23 days earlier. At the same time, the holding quality of green cuttings was on average $23-36 \%$ higher than that of untreated cuttings.

A similar situation was observed in the VSL-2 (Krymsky-5) graft, as in the CAB 6R graft. Analysis of the table data shows that the most rapid formation of callus bulges in VSL-2 (Krymsky-5) graft was recorded in an experimental variant treated with a water concentration of $80 \mathrm{mg} / 1 \mathrm{IMK}$, a growth-regulating substance in the basal part of green cuttings. In this variant, callus formation was recorded 8 days after the cuttings were planted in the substrate, which is 17 days earlier than the control. Further increase or decrease in the concentration of growth-regulating substance led to a slight slowing of rhizogenesis.

The onset of mass formation of roots in green cuttings in VSL-2 (Krymskiy-5) graft was also observed in the experimental variant of the growth control agent IMK treated with a water concentration of $80 \mathrm{mg} / \mathrm{l}$. In this experimental variant, the mass formation of roots began to occur 16 days after the cuttings were planted in the substrate, i.e. earlier than the control. In this regard, the recording of growth marks on the surface of green cuttings was also recorded in this variant at the earliest - on the 19th day after planting the cuttings.

It is also clear from the table data that there is no need to increase the concentration of the growth control agent IMK after $80 \mathrm{mg} / \mathrm{l}$. Because when the concentration was brought to $100 \mathrm{mg} / \mathrm{l}$ of water, similar results were obtained as in the previous experimental variant.

The concentration of working solutions of the growing material used in the processing of cuttings had different effects on the passage of regeneration phases and the rate of plant growth. Observations of subsequent developmental phases of rooted cuttings showed that the highest results were recorded in all variants of the experiment in cases where IMK was used at a water concentration of $80 \mathrm{mg} / \mathrm{l}$.

The developmental feature of the root system of cherry grafts was directly related to the intensity of the onset of rhizogenesis. In particular, it was observed that a strong root system was formed in the earliest experimental options for the development of the root system. In the experimental variants with the earliest and most rapid regeneration, a root system of the size with the highest performance was formed at the end of the growing season. Consequently, in the VSL-2 (Krymsky-5) graft, a root system was formed in the volume of 4.8 to $6.9 \mathrm{~cm}^{3}$, depending on the concentration of the growing substance, which is $0.5-2.6 \mathrm{~cm}^{3}$ higher than in the control.

The fact that regeneration processes took place at different times under the influence of the concentration of growth-regulating substance also led to differences in the height of the aboveground part of the experimental plants. As a rule, the tallest plants $(51.6$ and $53.2 \mathrm{~cm})$ in the $\mathrm{CAB} 6 \mathrm{P}$ graft were formed from rooted cuttings treated with water concentrations of 80 and $100 \mathrm{mg} / \mathrm{l} \mathrm{IMK}$. The average height of plants varied in the range of $36.3-42.8 \mathrm{~cm}$ in variants in which the concentration of the growth-regulating substance IMK was reduced (Table 2).

It should be noted that the diameter of the plant body is its most important quality indicator in the cultivation of grafted material. The diameter of the conditional body of the grafts propagated from the green cuttings (the upper part of the place where the first root was formed) also depended on the treatment of the cuttings with the growth control agent and its concentration. It is known from the practice of cutting grafts that when the diameter of the body of the grafted plant is $6-7 \mathrm{~mm}$, it is standard - that is, the bud is considered the most suitable size for grafting.

Determining the diameter of the green cuttings grown in the cutting grafts season (first half of August) showed that the standard size of the plant conditional body in CAB $6 \mathrm{P}$ grafts was recorded in the variants treated at growth concentrations of 40 to $100 \mathrm{mg} / \mathrm{l}$ water. At the same time, plants with the optimum body thickness $(7.9 \mathrm{~mm})$ were observed in the 
experimental variant in which green cuttings were grown by treating them with a water concentration of $80 \mathrm{mg} / \mathrm{l}$ of IMC.

Table 2. Growth control agent development characteristics of the root system and surface of green cuttings of cherry grafts treated with different concentrations of IMK (2017-2020).

\begin{tabular}{|c|c|c|c|c|c|}
\hline \multirow[b]{2}{*}{$\begin{array}{l}\text { Experiment } \\
\text { options }\end{array}$} & \multicolumn{5}{|c|}{ Indicators of rooted cuttings development } \\
\hline & $\begin{array}{c}\text { Roots in the } \\
\text { first order, } \\
\text { pcs }\end{array}$ & $\begin{array}{c}\text { Volume of } \\
\text { the root } \\
\text { system, } \mathrm{cm}^{3}\end{array}$ & $\begin{array}{c}\text { Plant } \\
\text { height, } \mathrm{cm}\end{array}$ & $\begin{array}{l}\text { Absolute body } \\
\text { diameter, mm }\end{array}$ & $\begin{array}{l}\text { Leaf area, } \\
\mathrm{cm}^{2}\end{array}$ \\
\hline \multicolumn{6}{|c|}{ CAB - $6 \mathrm{P}$} \\
\hline $\begin{array}{c}\text { Cuttings treated } \\
\text { with water - cont. }\end{array}$ & 14.3 & 4.1 & 33.7 & 5.5 & 322.7 \\
\hline IMK -20 mg/l & 15.6 & 4.3 & 36.3 & 5.9 & 328.9 \\
\hline IMK $-40 \mathrm{mg} / 1$ & 18.1 & 4.9 & 38.4 & 6.2 & 335.1 \\
\hline IMK -60 mg/1 & 20.2 & 5.3 & 42.8 & 7.5 & 340.7 \\
\hline IMK $-80 \mathrm{mg} / \mathrm{l}$ & 22.1 & 5.9 & 51.6 & 7.9 & 356.7 \\
\hline IMK $-100 \mathrm{mg} / 1$ & 21.3 & 6.1 & 53.9 & 7.9 & 377.8 \\
\hline$E K F_{05}$ & 1.7 & 0.7 & 2.9 & 0.4 & 0.6 \\
\hline$S_{x}, \%$ & 1.2 & 1.9 & 1.0 & 1.0 & 1.0 \\
\hline \multicolumn{6}{|c|}{ VSL-2 (Krimsky-5) } \\
\hline $\begin{array}{c}\text { Cuttings treated } \\
\text { with water - cont. }\end{array}$ & 18.7 & 4.3 & 35.3 & 4.9 & 228.3 \\
\hline IMK -20 mg/l & 19.9 & 4.8 & 38.6 & 5.1 & 231.4 \\
\hline IMK -40 mg/l & 21.3 & 5.3 & 41.7 & 5.5 & 238.7 \\
\hline IMK -60 mg/l & 23.4 & 5.9 & 49.9 & 6.1 & 241.3 \\
\hline IMK - $-80 \mathrm{mg} / 1$ & 25.1 & 6.9 & 58.9 & 7.1 & 252.6 \\
\hline IMK - $100 \mathrm{mg} / 1$ & 25.2 & 6.9 & 59.7 & 7.2 & 251.1 \\
\hline$E K F_{05}$ & 2.8 & 0.4 & 2.1 & 0.3 & 0.7 \\
\hline$S_{x}, \%$ & 1.8 & 0.9 & 0.6 & 0.7 & 1.0 \\
\hline
\end{tabular}

The data from the table show that the thickness of the conditional body of the cherry in the VSL-2 (Krymsky-5) graft also had a tendency to change depending on the concentration of the growth-controlling substance, as in the graft above. At the same time, the standard size of the conditional body diameter was noted in the experimental variants of the IMC treated with water concentrations of 60,80 and $100 \mathrm{mg} / \mathrm{l}$. in these experimental variants, the conditional body diameter of the developed plants was $1.2-2.3 \mathrm{~mm}$ higher than the control. Treatment of green cuttings of cherries in VSL-2 (Krymskiy-5) grafts with slightly lower IMC water concentrations - 20 and $40 \mathrm{mg} / \mathrm{l}$, led to their failure to reach the standard thickness by the cutting grafts season. In doing so, they varied the conditional body diameter in the range of 5.1-5.5 $\mathrm{mm}$ and differed from the control by only $0.2-0.6 \mathrm{~mm}$.

In addition to the effect of growth-regulating substance on the development indicators of plant leaf area, the sharp difference in graft types is explained by their genotype. As can be seen from the table above, although VSL-2 (Krymsky-5) graft has an advantage over CAB-6R graft with good rooting and growth, the overall leaf level was smaller in this graft type due to the thinness of the leaves (peach leaf oblong). $-231.4-251.1 \mathrm{~cm}^{2}$. Due to the size of the leaves in the CAB-6R graft, the average leaf area of one plant in them was also large $\left(322.7-377.8 \mathrm{~cm}^{2}\right)$.

The fact that the conditional body diameter of the grafted materials reached the standard size also had a significant effect on the change in the number of grafted plants. In plants grown from green cuttings of cherry CAB-6R graft, the lowest number of seedlings that did not reach the size suitable for cutting grafts in the second decade of August was recorded in the experimental variant treated with a water concentration of $80 \mathrm{mg} / \mathrm{l} \mathrm{IMK}$. In this variant, the amount of budded grafted plants reached $89 \%$ of the total number of rooted cuttings and was $68 \%$ higher than the control. The remaining $11 \%$ of the graft material was postponed for replanting next year. The number of grafted plants remained almost unchanged when the IMC concentration was brought to $100 \mathrm{mg} / \mathrm{l}$ of water. 
The data in Fig. 1 below show that a decrease in the concentration of IMC resulted in a proportional decrease in the number of plants grown to a thickness suitable for grafting. Consequently, if the number of plants grafted to green cuttings in the experimental variant treated with a water concentration of $60 \mathrm{mg} / \mathrm{l} \mathrm{IMC}$ was $71 \%$ of the total number of rooted plants, then in the experimental variants treated with water concentrations of 40 and 20 $\mathrm{mg} / \mathrm{l}$ IMK this figure 59 and $38 \%$, respectively. This led to an increase in the number of plants left to be replanted in the next year in the experimental options and approaching the level of the control option.

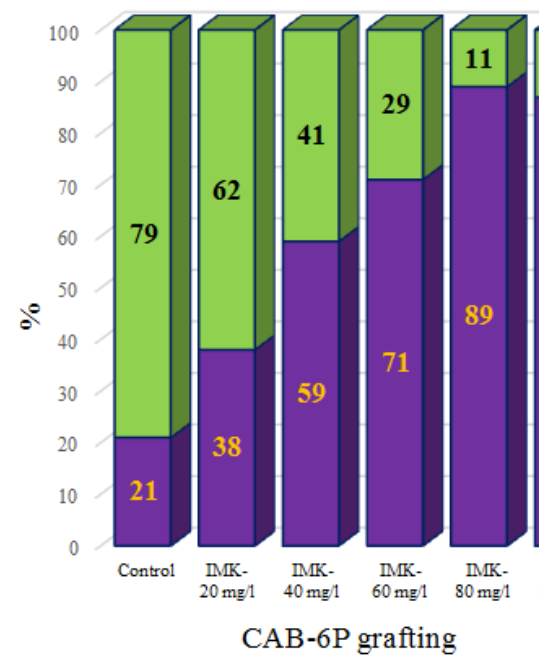

$\square$ Failed cuttings in root taking
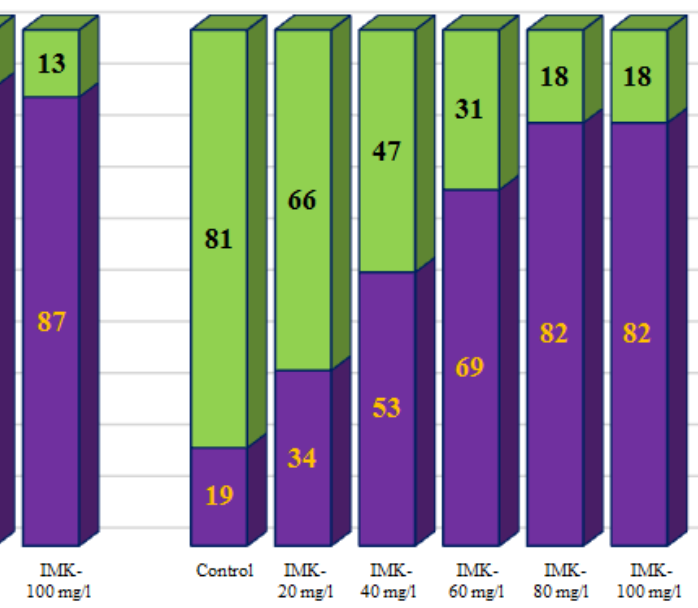

VSL-2 grafting

Successfully grafted cuttings

Fig. 1. Influence of IMK concentration on cherry grafts grown from green cuttings to reach the appropriate size for cutting grafts.

The picture data show that even in the VSL-2 (Krymsky-5) graft, the amount of plants that reached the thickness suitable for cutting grafts changed in the same trend as in the CAB-6R graft. However, in the general case, the amount of plants that could be grafted was slightly less in this graft than in the CAB-6R grader, regardless of the IMK concentration. This condition is explained by the genotype of the plant, i.e., that it has a slightly thinner body.

In the experiments of a number of scientists, it was noted that the time of preparation of cuttings in the propagation of vegetatively propagated woody plants from green cuttings also has a high impact on their root yield [7, 8].

Preparing the cuttings too early, i.e. when the twigs are still too soft and delicate, will result in their many deaths. On the contrary, taking too late, when the branches have reached full woodiness, also leads to a decrease in rhizogenesis in them.

It is also hypothesized that the part of the branch from which the cuttings are derived also affects the rhizogenesis processes that take place in them [4]. Because, as a rule, if the third part is very thin and sharp, the middle and lower parts are a little woody, and at the same time have accumulated a certain amount of spare nutrients. Therefore, finding the most moderate period of pruning allows maximizing their rooting efficiency. It should be borne in mind that such a period of woody plants, which can reproduce in any vegetative way, is its individual biological feature and may vary depending on the type of plant, place of growth and its soil-climatic conditions.

In order to determine such a period in vegetatively propagated grafts of cherries, experiments were carried out on VSL-2 (Krimsky-5) graft, which is characterized by good 
rooting. In our experiments, green cuttings in VSL-2 (Krimsky-5) graft were prepared and planted every ten days from the first ten days of May to the end of June. Green cuttings were cut separately from the lower, middle and third apical parts of the branch to a length of $8-10 \mathrm{~cm}$ and prepared separately. Before planting, the basal part of the green cuttings was treated for 16 hours with a growth control agent - IMK water concentration of $80 \mathrm{mg} / \mathrm{l}$. The cuttings were then planted at a depth of 4-5 cm in cassettes filled with an artificial substrate consisting of a mixture of coarse river sand and humus in a 1: 1 ratio, the upper part of which was covered with a large river sand $5 \mathrm{~cm}$ thick, as in the previous experiment. The grafts were grown in film greenhouses where the internal microclimate is controlled (artificial fog is created).

Observations of regeneration processes in green cuttings prepared from different periods and different parts of the branch showed that the timing of cutting green cuttings from the growing branch this year and from which part of the branch it was obtained had a significant impact on the intensity and quality of rhizogenesis. Consequently, the rhizogenesis and regeneration processes were more intense in the cuttings obtained from the lower part of the branch during all periods of pruning (Fig. 2).

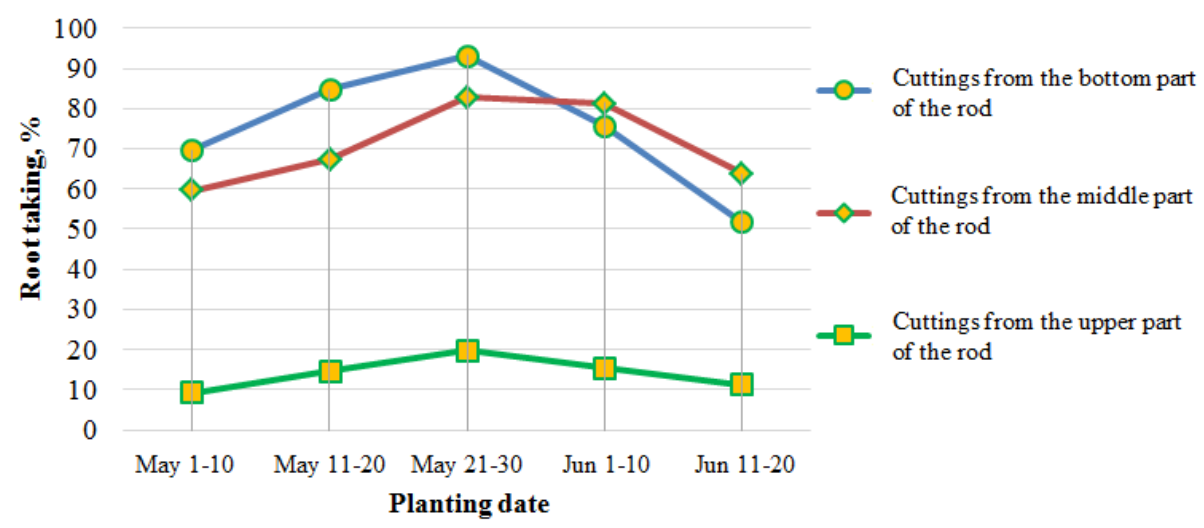

Fig. 2. Influence of vegetatively propagated cherries VSL-2 (Krimsky-5) on rooting of green cuttings, their preparation time and rod part.

Fig. 2 showed that the root yield of green cuttings was also slightly higher in cuttings taken from the middle part of the branch, and by the end of May, their root yield reached $92.8 \%$. The slowest $(9.3-19.8 \%)$ rooting was recorded in cuttings prepared from the third layer of the branch.

The vegetative propagation of cherries by vegetatively propagated VSL-2 (Krimsky-5) had a particularly high effect on the rooting of green cuttings, their ripening time. The highest rooting was recorded in the last ten days of May, regardless of which part of the branch the cuttings were prepared. When green cuttings were prepared and planted during this period, their root yield reached 93.2 and $92.8 \%$, respectively, in cuttings prepared from the lower and middle part of the branch. Cuttings made from the third stem of the branch, although significantly lower than the root yield of the lower and middle cuttings, were at a higher rate than in other periods and accounted for $18.8 \%$.

From a production point of view, in addition to the rooting of green cuttings, it is also very important that by the time of cutting grafts, the diameter of the conditional root collar reaches the standard size $(6-7 \mathrm{~mm})$. The most favorable period for cherries - biometric measurements carried out in the second decade of August showed that, regardless of the time of preparation, cuttings prepared from the lower and middle parts of the branch were conditionally rooted diameter of the standard size and above. In cuttings prepared from the third part of the branch, this biometric indicator reached a thickness of 6-7 mm only when 
planted in May. Delaying the preparation and planting time does not ensure that they reach a diameter sufficient for cutting grafts (Fig. 3).

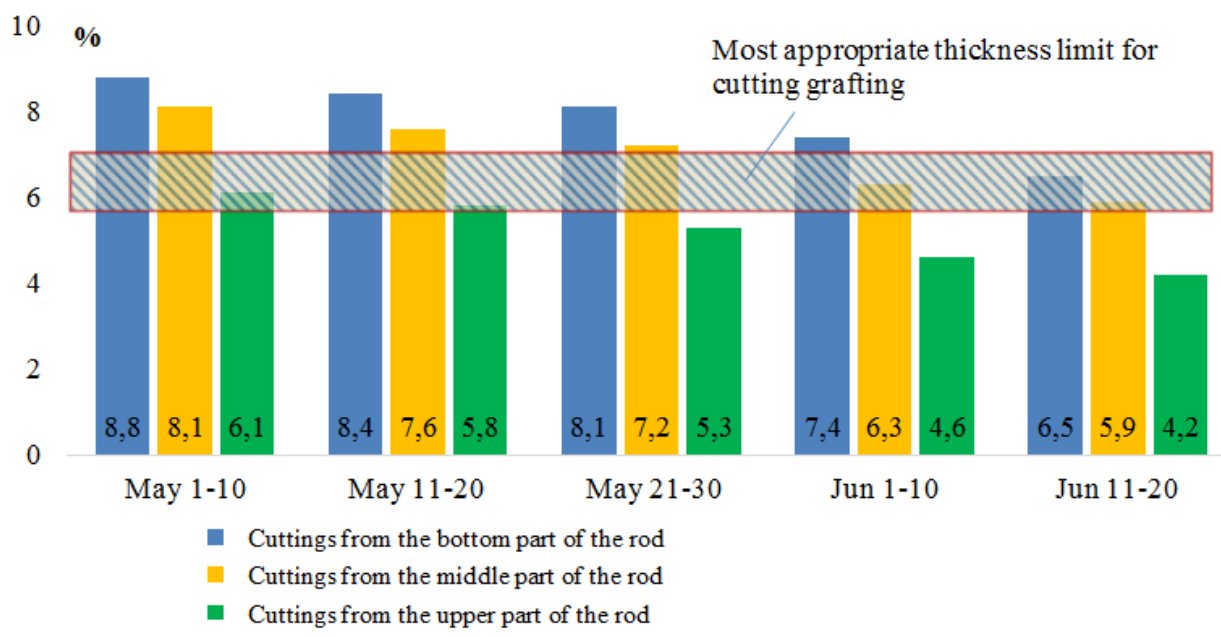

Fig. 3. Influence of VSL-2 (Krimsky-5) grafted plants grown from green cuttings on the conditional root canal thickness, planting time of cuttings and the part of the stem from which they were obtained, in $\%$.

\section{Conclusions}

1. In the propagation of vegetatively propagated CAB-6R and VSL-2 (Krimsky-5) cherries from green cuttings, treatment with a growth regulator in the basal part of cuttings $-80 \mathrm{mg} / \mathrm{l}$ aqueous solution of IMK allows them to achieve rhizogenesis up to $78-81 \%$. At the same time, the root quality of green cuttings is on average $23-36 \%$ higher than that of untreated cuttings.

2. Rapid and early regeneration processes in green cuttings using the optimal concentration of IMK ensure that their conditional body diameter reaches the standard (6-7 $\mathrm{mm})$ size before the cutting grafts season. In such grafting materials, the number of plants that can be grafted buds is ensured to increase by about $89 \%$ relative to the total number of rooted plants.

3. When propagating vegetatively propagated CAB-6R and VSL-2 (Krimsky-5) cherries from green cuttings of cherries, it is best to prepare these cuttings from the lower and middle parts of the branch. Plants grown from cuttings prepared from this part of the branch, the diameter of the conditional root collar reaches $6.5-8.8$ and $5.9-8.1 \mathrm{~mm}$, respectively, by the time of cutting grafts season (August 10-20).

4. The most effective processes of rhizogenesis and regeneration in green cuttings are recorded when green cuttings are prepared and planted in the last ten days of May. In this case, the root yield of green cuttings of CAB-6R and VSL-2 (Krimsky-5) grafts reaches 93.2 and $82.8 \%$, respectively, in the variants prepared from the lower and middle parts of the branch.

\section{References}

1. P. Schwalb. W. Feucht, Advances in Horticultural Science, 71-75 (1999) 
2. A. Mansseri-Lamrioui, A. Louerguioui, J. Bonaly, S. Yakoub-Bougdal, N. Allili, S. Gana-Kebbouche, African Journal of Biotechnology, 10(43), 8613-8624 (2011)

3. Kh.Ch. Buriev, N.Sh. Enileev, Methods of calculations and phenological observations in experiments with fruit and berry plants, 64 (Sharq publications, Tashkent, 2014)

4. V.S. Savenko, R.A. Kulmatov, Geochemistry International, 35(11), 1028-1030 (1997)

5. B.S. Ermakov, Reproduction of woody and shrub plants by green cuttings, 48 (Shtiinica Publications, Kishinev, 1981)

6. R.A. Kulmatov, A.A. Kist, IND. LAB, 44(12), 1689-1692 (1978)

7. C. Ma, Z. Sun, C. Chen, L. Zhang, S. Zhu, Food chemistry, 145, 784-788 (2014)

8. V. Sarropoulou, K. Dimassi-Theriou, I. Therios, Horticultural Science, 42(4), 185-192 (2015)

9. İ. Damar, A. Ekşi, Food chemistry, 135(4), 2910-2914 (2012)

10. F.Ya. Polikarpova, V.V. Pilyugina, Rosagropromizdat, 23-31 (1991)

11. I. Mitre, V. Mitre, A. Sestras, R. Sestras, Bulletin of UASVM Cluj-Napoca. Horticulture, 68(1), 97-102 (2011)

12. X. Li, Y. Wei, J. Xu, X. Feng, F. Wu, R. Zhou, Y. He, Postharvest Biology and Technology, 143, 112-118(2018) 